\title{
Study of various demographic factors affecting average rate of cooling of cadavers in tropical climate of central India
}

\author{
Ashish Jain ${ }^{1}$, Jayanthi Yadav², Sujeet Kumar Samadder,"* \\ ${ }^{\mathbf{1}}$ Associate Professor, Dept. of Forensic Medicine \& Toxicology, Gandhi Medical College, Bhopal, Madhya Pradesh, ${ }^{\mathbf{2}}$ Additional \\ Professor, Dept. of Forensic Medicine \& Toxicology, All India Institute of Medical Sciences, Bhopal, Madhya Pradesh, \\ ${ }^{3}$ Assistant Professor, Dept. of Forensic Medicine \& Toxicology, Mahaveer Institute of Medical Sciences, Bhopal, Madhya \\ Pradesh, India
}

*Corresponding Author:

Email: drsujeet2522@gmail.com

\begin{abstract}
Introduction: To understand the different aspects of average rate of cooling (ARC) in detail, is very important step for understanding algor mortis in order to determine time since death in early post-mortem interval, as the classic triad of so-called thanatochronological data is constituted by algor mortis, rigor mortis and livor mortis. This paper is a humble trial to show some light in the direction of average rate cooling of cadavers in relation to different demographic indicators, personal and environmental effects in tropical climate of central India.

Materials and Methods: A cross sectional study was carried out on 173 randomly selected cadavers which were brought for autopsy in department of Forensic Medicine \& Toxicology, Gandhi Medical College, Bhopal. Following data were collected age, gender, height, weight, ambient room temperature and rectal temperature. Data was analysed by using SPSS software.

Result: Average rate of cooling was found - more in males $\left(1^{\circ} \mathrm{F} /\right.$ hour $)$ as compared to females $\left(0.8^{\circ} \mathrm{F} / \mathrm{hour}\right)$, more in underweight persons $\left(1.2^{\circ} \mathrm{F} / \mathrm{hour}\right)$ as compared to obese $\left(0.7^{\circ} \mathrm{F} /\right.$ hour $)$, more in cold environment $\left(1.8^{\circ} \mathrm{F} /\right.$ hour $)$ as compared to hot environment $\left(0.7^{\circ} \mathrm{F} /\right.$ hour $)$, and extreme age group was found to have extreme rate of cooling.
\end{abstract}

Keywords: Post-mortem cooling, Time since death, Average rate of cooling, Ambient room temperature, Algor mortis, Cadaver.

\section{Introduction}

During early post-mortem interval algor mortis is an indispensable part in determination of time since death (TSD). Other important methods for determination of TSD are rigor mortis, livor mortis, and biochemical changes in blood, serum, cerebrospinal fluid etc. But so far no single method is capable of telling the TSD precisely. Algor mortis is cooling of the cadaver due to loss of heat owing to difference of temperature between the cadaver and environment. This sets temperature gradient from core to surface of cadaver, core being the hottest and surface the coolest. Heat dissipation from cadaver to environment occurs at $1.5^{\circ} \mathrm{F} /$ hour and $0.7{ }^{\circ} \mathrm{F} /$ hour in temperate in tropical climate respectively ${ }^{1}$ which is known as average rate of cooling (ARC). On the basis of ARC TSD can be determined precisely. This paper aims to study ARC in relation to various demographic factors and also in different time slots and different environmental conditions. Rectal route is the ideal route for measurement of core body temperature. Rectal temperature ranges from $36.5^{\circ} \mathrm{C} /$ hour to $37.5^{\circ} \mathrm{C} /$ hour. ${ }^{1}$

\section{Materials and Methods}

A cross-sectional observational study was conducted at department of Forensic Medicine \& Toxicology, Gandhi Medical College, Bhopal during the period of July 2015 to August 2016.

A total of 173 cadavers brought for medicolegal autopsy were randomly selected for this study. Those cases in which time of death was known and documented were included and those in which time of death was not known and the body temperature at the time of death was either high or sub-normal were excluded. The post-mortem requisition form, along with the inquest papers, were received from the police. The cadavers were studied in the same condition in which they were brought. Minimal disturbances was done as far as possible with regard to clothings and coverings.

Exact time since death was recorded from hospital records and police documents. After noting the external appearance, the clothings were removed and rectal temperature was recorded in supine position, after spreading both legs apart exposing the perineal region. Laboratory thermometer of length 32 centimetres with a temperature range of 0 to 50 degree centigrade was inserted 10 centimetre deep in rectum of cadaver. The reading was noted down two minutes after keeping the thermometer inside the rectum, then thermometer was taken out. Simultaneously ambient temperature was also recorded with ambient temperature thermometer. Further details such as age, gender, built, height, weight, actual time of death, time of reading of rectal temperature etc. are noted down from the documents and history. Average rate of cooling was calculated using the formula:

$\mathrm{ARC}=\sum \mathrm{RC} / \mathrm{n}$

ARC - Average rate of cooling, RC - Rate of cooling of each cadaver, $\mathrm{n}$ - number of cadavers.

$\mathrm{RC}=\left(\mathrm{t}-\mathrm{t}^{1}\right) /$ known TSD in hours

$t-$ Rectal temperature of cadaver at the time of death, $t^{1}$

- Rectal temperature at the time of autopsy.

Data was analysed by using SPSS software. 


\section{Results}

In the present study total number of cases were $\mathrm{n}=173$. Mean average rate cooling (ARC) was found to be $1{ }^{\circ} \mathrm{F} /$ hour which was found to statistically significant $(\mathrm{P}<0.05)$.

ARC was found to be highest in old age extreme (71 to 80 years, $\mathrm{n}=04$ ) $1.3^{\circ} \mathrm{F} /$ hour, and lowest in young age extreme (01 to 10 years, $n=02$ ) $0.4^{\circ} \mathrm{F} /$ hour. The most common ARC was $0.9^{\circ} \mathrm{F} /$ hour found in 74 cases of which 50 cases in the age group 21 to 30 years and 24 cases in the age group of 41 to 50 years) which was found to statistically significant $(\mathrm{P}<0.05)$.

ARC was more in males $(n=136) 1^{\circ} \mathrm{F} /$ hour as compared to females $(\mathrm{n}=37) 8^{\circ} \mathrm{F} /$ hour which was found to statistically significant $(\mathrm{P}<0.05)$.

The number of overweight and normal weight cadavers were $79(45.7 \%)$ and $76(43.9 \%)$ respectively, rest are either underweight or obese. ARC was highest $\left(1.2{ }^{\circ} \mathrm{F} /\right.$ hour $)$ in underweight group and lowest $\left(0.7^{\circ} \mathrm{F} /\right.$ hour $)$ in obese group which was found to statistically significant $(\mathrm{P}<0.05)$.

In the present study ARC was calculated in continuous time slots of 3 hours respectively, which came to be $1{ }^{\circ} \mathrm{F} /$ hour for first 3 hours, then ARC peaks to $1.3{ }^{\circ} \mathrm{F}$ /hour for 3 to 6 hours, then shows decreasing trend as follows $-1.1{ }^{\circ} \mathrm{F} /$ hour for 6 to 9 hours, 1 ${ }^{\circ} \mathrm{F} /$ hour for 9 to 12 hours, $0.9{ }^{\circ} \mathrm{F} /$ hour for 12 to 18 hours, $0.6^{\circ} \mathrm{F} /$ hour for 18 to 24 hours. ARC is relatively less in early three hours after death, then reaches its maximum in 3 to 6 hours then rate of cooling decline as the time passes.

Table 5 shows effect of environmental temperature on rate of cooling, as the ARC was $1.8 \& 0.7^{\circ} \mathrm{F} /$ hour at environmental temperature of $\left\langle 23{ }^{\circ} \mathrm{C} \&>23{ }^{\circ} \mathrm{C}\right.$ respectively. It was evident that when there is a large difference between environment and the core body temperature, the rate of cooling is more and vice versa which is in accordance with the "Newton's Law of Cooling" i.e. rate of cooling is directly proportional to temperature difference between two surfaces.

Table 1: Frequency distribution in age and gender of samples

\begin{tabular}{|l|c|c|c|c|}
\hline \multirow{2}{*}{$\begin{array}{c}\text { Age groups in } \\
\text { years }\end{array}$} & \multicolumn{2}{|c|}{ Gender } & \multirow{2}{*}{ Total Number of samples } & \multirow{2}{*}{ ARC in ${ }^{\circ} \mathbf{F} / \mathbf{h o u r}$} \\
\cline { 2 - 4 } & Male & Female & & \\
\hline $1-10$ & 1 & 1 & 2 & 0.4 \\
\hline $11-20$ & 25 & 11 & 36 & 1.0 \\
\hline $21-30$ & 37 & 13 & 50 & 0.9 \\
\hline $31-40$ & 28 & 7 & 35 & 1.1 \\
\hline $41-50$ & 23 & 1 & 24 & 0.9 \\
\hline $51-60$ & 13 & 2 & 15 & 1.1 \\
\hline $61-70$ & 6 & 1 & 7 & 0.8 \\
\hline $71-80$ & 3 & 1 & 4 & 1.3 \\
\hline Total & 136 & 37 & 173 & \\
\hline
\end{tabular}

Table 2: Frequency distribution of ARC gender-wise

\begin{tabular}{|l|c|c|}
\hline \multicolumn{1}{|c|}{ Gender } & $\begin{array}{c}\text { ARC in } \\
{ }^{\circ} \text { F/hour }\end{array}$ & $\begin{array}{c}\text { Number of } \\
\text { samples }\end{array}$ \\
\hline Male & 1.0 & 136 \\
\hline Female & 0.8 & 37 \\
\hline
\end{tabular}

Table 3: Frequency distribution ARC in relation to BMI with WHO BMI categorisation

\begin{tabular}{|l|c|c|}
\hline \multicolumn{1}{|c|}{ Built (BMI) } & $\begin{array}{c}\text { ARC in } \\
{ }^{\circ} \text { F/hour }\end{array}$ & $\begin{array}{c}\text { Number } \\
\text { of samples }\end{array}$ \\
\hline $\begin{array}{l}\text { Underweight }(<18.5 \\
\left.\mathrm{kg} / \mathrm{m}^{2}\right)\end{array}$ & 1.2 & 6 \\
\hline $\begin{array}{l}\text { Normal }(18.5-25 \\
\left.\mathrm{kg} / \mathrm{m}^{2}\right)\end{array}$ & 1.0 & 76 \\
\hline $\begin{array}{l}\text { Overweight }(25-30 \\
\left.\mathrm{kg} / \mathrm{m}^{2}\right)\end{array}$ & 0.9 & 79 \\
\hline Obese $\left(>30 \mathrm{~kg} / \mathrm{m}^{2}\right)$ & 0.7 & 12 \\
\hline
\end{tabular}

Table 4: Frequency distribution of ARC in different time slots

\begin{tabular}{|l|c|c|c|}
\hline Time Interval & $\begin{array}{c}\text { ARC in } \\
\text { 'F/hour }\end{array}$ & $\begin{array}{c}\text { ARC in } \\
{ }^{\mathbf{}} \mathbf{C} / \mathbf{h o u r}\end{array}$ & $\begin{array}{c}\text { Sample } \\
\text { Size }\end{array}$ \\
\hline 0 to 3 hours & 1.00 & 0.57 & 12 \\
\hline 3 to 6 hours & 1.3 & 0.74 & 29 \\
\hline 6 to 9 hours & 1.1 & 0.60 & 27 \\
\hline 9 to 12 hours & 1.0 & 0.52 & 23 \\
\hline 12 to 15 hours & 0.9 & 0.50 & 31 \\
\hline 15 to 18 hours & 0.9 & 0.48 & 27 \\
\hline 18 to 21 hours & 0.6 & 0.35 & 16 \\
\hline 21 to 24 hours & 0.6 & 0.31 & 08 \\
\hline
\end{tabular}

Table 5: Frequency distribution of cases of ambient temperature $>23$ and $<23{ }^{\circ} \mathrm{C}$

\begin{tabular}{|c|c|c|}
\hline $\begin{array}{c}\text { Environmental } \\
\text { temperature }\end{array}$ & $\begin{array}{c}\text { ARC in } \\
{ }^{\circ} \mathbf{F} / \text { hour }\end{array}$ & $\begin{array}{c}\text { Number of } \\
\text { cases }\end{array}$ \\
\hline$<23^{\circ} \mathrm{C}$ or $73.4^{\circ} \mathrm{F}$ & 1.8 & 129 \\
\hline$>23^{\circ} \mathrm{C}$ or $734^{\circ} \mathrm{F}$ & 0.7 & 44 \\
\hline
\end{tabular}


Table 6: Relationship between Average Atmospheric Temperature (AAT) and average rate of cooling (ARC) per hour

\begin{tabular}{|l|c|c|}
\hline AAT in degree C & No. of cases & $\begin{array}{c}\text { ARC degree } \\
\text { C/hour }\end{array}$ \\
\hline $10-15$ & Nil & Nil \\
\hline $16-20$ & $4(2.43 \%)$ & 0.53 \\
\hline $21-25$ & $56(34.14 \%)$ & 0.50 \\
\hline $26-30$ & $39(23.78 \%)$ & 0.49 \\
\hline $31-35$ & $58(35.39 \%)$ & 0.35 \\
\hline $36-40$ & $7(4.26 \%)$ & 0.22 \\
\hline
\end{tabular}

\section{Discussion}

This cross-sectional study was conducted on 173 cadavers for estimation of time since death by the algor mortis in early post-mortem interval. In this study rectal temperature, height and weight were measured of those cadavers whose time of death was known. Average rate of cooling (ARC) was calculated and compared statistically on the basis of age, gender, built, in different time slots, environmental changes.

Average rate of cooling (ARC) of study population in the present study was $1^{\circ} \mathrm{F} /$ hour or $0.5^{\circ} \mathrm{C} /$ hour. Our results resembles to study conducted by Nanadkar S D et al (1994) ${ }^{2}$ and Basu S K et al (1984). ${ }^{3}$ In their study ARC was $0.43{ }^{\circ} \mathrm{C} /$ hour $0.4^{\circ} \mathrm{C} /$ hour respectively. A mild discrepancy was noted which may be due to warmer environmental temperature of Aurangabad region in comparison to Bhopal region as Aurangabad is more close to equator.

Our results contrast with the results of Wilkie Burman $(1847)^{4}$ who reported ARC of $1.6^{\circ} \mathrm{F} /$ hour since there study of temperate climate. Robertson W G Aitchison $(1925)^{4}$ reported ARC in first 3 hours after death of $3.5^{\circ} \mathrm{F} /$ hour in robust built and $4.5^{\circ} \mathrm{F} /$ hour in emaciated person, in the next 3 hours ARC is $3{ }^{\circ} \mathrm{F} /$ hour commonly in both types of built. Keith Simpson $(1965)^{5,6}$ mentioned that ARC in first 6 hours is 2.5 ${ }^{\circ} \mathrm{F} /$ hour or $1.5-2{ }^{\circ} \mathrm{F} /$ hour in first 12 hours. Laxman J B $(1979)^{7}$ reported ARC to be $0.7-0.8^{\circ} \mathrm{F} /$ hour. Spitz and Fishers $(1993)^{8}$ stated that ARC in $1^{\text {st }}$ hour after death is $2-2.5^{\circ} \mathrm{F} /$ hour and $1.5-2^{\circ} \mathrm{F} /$ hour in $1^{\text {st }} 12$ hours and 1 ${ }^{\circ} \mathrm{F} /$ hour in next $12-18$ hours. The above discrepancies for different temperature recording of different researchers may have come as a result of difference in environmental temperature from India, as most of the studies are done in temperate climate where average temperature of environment is low so rate of cooling will be more.

Maximum ARC was seen in age group of 71-80 years which was $1.3{ }^{\circ} \mathrm{F} /$ hour. This result matches with the observation made by Robertson W G Aitchison $1925,{ }^{4}$ the reason for this observation is due to less body mass and surface area. Minimum ARC is observed in 01-10 years age group which is $0.4^{\circ} \mathrm{F} /$ hour. The literature says that ARC is more in extremes of ages such as in infants and old-age but no data is given to support this. The reason behind this discrepancy is explained by Keith Simpson $(1965)^{9}$ who stated in "Taylor's principles and practice of medical jurisprudence" that children cool down more rapidly than the average adult although their actual heat loss per unit of time will be less over the same ranges of temperature as compared to adult bodies.

In the present study, out of 173 sample size males are $136(78.6 \%)$ with ARC of $1.0^{\circ} \mathrm{F} /$ hour and females are $37(21.4 \%)$ with ARC of $0.8^{\circ} \mathrm{F} /$ hour. Clearly males cool down at a faster rate than females as females have more subcutaneous fat which is bad conductor of heat and act as insulating blanket to heat dissipation as supported by Kuroda Fusakuni et $a^{10}$ 1982. Karl Sellier ${ }^{11}$ in 1948 mentioned that body fat does not work as an insulator to heat rather it provides more tissue covering to the core to not to dissipate the heat easily.

In the present study number of overweight and normal person are $79(45.7 \%)$ and $76(43.9 \%)$, rest are either underweight or obese. ARC of underweight, normal, overweight and obese category were 1.2, 1.0, $0.9,0.7^{\circ} \mathrm{F} / \mathrm{hour}$. So it is clear from the above data that ARC decreases as the BMI increases, which is due to less heat dissipation due to more mass on the body core. Gordon I, Shapiro H A and Berson S D ${ }^{12}$ (1988), Mukherjee J B ${ }^{13} 1994$ mentioned that well-built cadaver cools down slowly as compared to thin-built cadaver.

ARC in different time slot in our study was as follows. ARC in 0 to 6 hours, 7 to 12 hours, 13 to 18 hours, 19 to 24 hours are $1.31,1.00,0.90,0.62{ }^{\circ} \mathrm{F} /$ hour respectively. So it can be concluded that, as the postmortem interval increases, ARC decreases, which has been supported by Nanadkar S D et al $(1994)^{2}$ in their study. Thus they concluded that cooling was relatively slow in first three hours, maximum in three to six hours and declined progressively till equilibrium as the temperature of cadaver approached that of the surrounding. Present study result also concludes that cooling of body curve follows the sigmoid double exponential curve.

In the present study the ARC was $1.8 \& 0.7$ ${ }^{\circ} \mathrm{F} /$ hour at environmental temperature of $\left\langle 23{ }^{\circ} \mathrm{C} \&\right\rangle 23$ ${ }^{\circ} \mathrm{C}$ respectively, so it can be clearly stated that ARC is inversely proportional to environmental temperature, which supported in all literatures as Taylor Alfred Swaine and Wilkes ${ }^{4}$ 1865, De Saram, Webster, Kathirgamatamby ${ }^{4,14} 1955$. Further Nanadkar S D et $\mathrm{al}^{2}$ in 1994 illustrated in their study as shown in the table no. 6, that cooling was slow at high atmospheric temperature thus suggest presence of inverse relationship between average atmospheric temperature (AAT) and average rate of cooling (ARC) per hour i.e. cooling rate was high $\left(0.49^{\circ} \mathrm{C}\right)$ in winter than in summer $\left(0.37^{\circ} \mathrm{C}\right)$. Thus cooling of body does follow Newton's law of cooling to some extent. 


\section{Conclusion}

This study suggest that average rate of cooling in the study sample is $1.0^{\circ} \mathrm{F}$ or $0.54^{\circ} \mathrm{C}$. Males cool more rapidly than females. Extreme age group have extreme rate of cooling. ARC is inversely proportional to BMI. It was observed that cooling was inversely proportional to environmental temperature, not against Newton's law of cooling per se. It was observed that ARC was found to be slow initially and became rapid after three hours of death, then again decreased as temperature difference between cadaver and environment decreases, following a sigmoid shaped curve.

\section{References}

1. Sinha U S, Sahai V B, Singh G. The time since death with cooling of cadaver as indicator. Indian academy of Forensic Medicine- Feb 1981; $4^{\text {th }}$ annual conference.

2. Nanadkar S D, Deshpande V L. Effects of atmospheric temperature on cadaveric cooling. Medicolegal Association of Maharashtra. 1994:Vol. 1-11.

3. Basu S C. Handbook of Medical jurisprudence and Toxicology, $2^{\text {nd }}$ edition, 1984, 58-59.

4. Knight Bernard, Henssege Claus, Krompecher Thomos, Madea Barkhard, Nokes Leonard, Edited by Bernard Knight, The estimation of time since death in early postmortem period Edward Arnold Publication, London. 1995;4-35.

5. Marshall T K. The use of body temperature in estimating the time of death and its limitations. Medicine science and Law, 1969;9:178-182.
6. Owens T F. examination of the death. Lyon's Medical jurisprudence for India. $9^{\text {th }}$ edition. 1935;114-115.

7. Laxman B Joshi. Algor mortis (postmortem cooling). Medical News Medicine and Law. June 1979; Vol 5:224232.

8. Spitz and Fishers. Time of death and changes after death. Medicolegal investigation of death, postmortem examinations. $3^{\text {rd }}$ edition. 1993.22-23.

9. Simpson K. Death and Postmortem Changes. Taylor's principles and practice of medical jurisprudence. $12^{\text {th }}$ edition. 1965. 73-77.

10. Kuroada Fusakuni, Hiraiwa Kouchi Oshida Shegemi, Akaishi Suguru. Estimation of postmortem interval from rectal temperature by use of computer (III) - Thermal conductivity of the skin. Medicine Science and Law1982;22(4):285-289.

11. Green M A and Wright J C. The theoretical aspects of the time dependent $\mathrm{Z}$ equation as a mean of postmortem interval estimation using body temperature data only. Forensic Science International-1985;28:53-62.

12. Gordon 1, Shapiro H A. Diagnosis and the early signs of death. Text book of Forensic Medicine, 2nd edition, 1988, 12-18.

13. Mukherjee J B. Death and its medicolegal aspects. Forensic medicine and toxicology, $2^{\text {nd }}$ edition, Vol-1:1994, 213-218.

14. De Saram G S W, Webster G, Kathirgamatamby N. PostMortem Temperature and the Time of Death. J. Crim. L. Criminology - 1956;46(4):562-577. 